\title{
The Impact of Different Radiotherapy Techniques on Treatment Outcome of Hypopharyngeal Carcinomas in Routine Clinical Practice
}

BARBAROS AYDIN ( $\nabla$ barbaros_aydin@hotmail.com )

Dokuz Eylül University

Oguz Cetinayak

Dokuz Eylül University

\section{Asli Cakir}

Dokuz Eylül University

Cenk Umay

Dokuz Eylül University

\section{Nesrin Akturk}

Dokuz Eylül University

Nuri Karabay

Dokuz Eylül University

Fadime Akman

Dokuz Eylül University

\section{Research Article}

Keywords: radiotherapy techniques, hypopharyngeal carcinomas, clinical practice, treatment outcome

Posted Date: May 18th, 2021

DOI: https://doi.org/10.21203/rs.3.rs-523223/v1

License: (1) This work is licensed under a Creative Commons Attribution 4.0 International License. Read Full License 


\section{Abstract}

Purpose: The purpose was to evaluate the outcomes of different radiotherapy techniques used in routine clinical practice for the radical treatment of hypopharyngeal cancer and the improvement of outcomes over the last decades.

Methods: We compared 2D-RT, 3D-CRT and VMAT techniques and the improvement of outcomes over the last decades in patients with hypopharyngeal squamous cell carcinoma treated with curative radiotherapy (RT) or chemoradiotherapy between January 1992 and December 2016. Eighty-one patients with hypopharyngeal cancer were analyzed retrospectively.

Results: The median follow-up time was 15 (2-266) months. Radiotherapy technique $(p=0.049, p=0.025)$, KPS $(p<0.001, p=0.002)$, nodal stage $(p=0.012, p=0.026)$ and clinical stage $(p=0.029, p=0.035)$ were statistically significant factors affecting overall survival and local regional relapse-free survival in multivariate analysis. Grade 2-4 early and late side effects were significantly more frequent in Group I (2D Conventional Radiotherapy) (\%20.3) patients than in Group II (3DCRT, IMRT and VMAT technique) (\%3.1) $(p=0.04, p=0.038)$.

Conclusion: KPS, stage and advanced RT techniques independently affected outcomes significantly. Side effects are significantly reduced with advanced RT techniques.

\section{Introduction}

Hypopharyngeal squamous cell carcinoma (HSCC) is an aggressive cancer representing approximately 3$5 \%$ of all head and neck squamous cell cancers [1]. The standard treatment for hypopharyngeal cancer is surgery and/or radiotherapy (RT). The choice of treatment modality may vary depending on tumor localization, stage, operability and clinical experience of the physician. Surgery or RT alone can be used in early-stage tumors without regional lymph node involvement whereas concurrent chemoradiotherapy (CRT) seems the best option when the anatomic location and spread of the tumor restrict surgical resection [2, 3, 4]. Hypopharyngeal cancers are diagnosed mostly in advanced stages. Surgical management leads to disruption of speech, organ dysfunction, difficulties in closing the defect after surgery and concerns patients' quality of life. Therefore, non-surgical treatments gain importance in recent years $[5,6,7]$. In a study published by the European Organization for Research and Treatment of Cancer (EORTC) in 1996 and an update of this study which was published in 2012 larynx could be preserved in $59.5 \%$ of patients who lived for 5 years with definitive RT after induction chemotherapy [8, 9]. EORTC trial 24891 focused specifically on hypopharynx cancer and demonstrated that an organ-preserving approach of induction, followed by radiotherapy leads to similar outcomes than surgery [9]. Many centers have accepted organpreserving concomitant CRT protocols with or without induction chemotherapy and salvage surgery as the standard of care for the treatment of hypopharyngeal cancers. During the past decade developments in RT technology have brought notable advances. Based on computed tomography (CT) three-dimensional conformal RT (3DCRT), intensity-modulated radiation therapy (IMRT) and volumetric arc therapy (VMAT) had much superiority to conventionally RT (2DRT) in delivering high doses accurately to the target and sparing normal tissues. These modern systems have enabled radiation oncologists to significantly reduce 
side effects. In this study, we retrospectively compared the long-term treatment results of patients with hypopharyngeal cancer who underwent definitive RT with conventional 2D (Group I) and 3DCRT/VMAT (Group II) RT technique in accordance with our treatment protocol.

\section{Material And Methods}

\section{Patients}

In this study, 81 patients with histologically confirmed squamous cell carcinoma of the hypopharynx treated with curative RT or CRT between January 1992 and December 2016 were retrospectively analyzed. Pretreatment evaluation consisted of full medical history, clinical examination, blood sample, imaging of the primary site and neck by CT or magnetic resonance imaging (MRI), chest x-ray (thorax CT was performed in case of advanced-stage disease or if a suspicious lesion is detected in chest x-ray). In the case of clinical suspicion, bone scintigraphy and liver ultrasonography were performed. After the year 2010, all patients with locally advanced disease were evaluated with whole-body positron emission tomography (PET-CT). Histopathological diagnosis is achieved after primary tumor biopsy by direct laryngopharyngoscopy under general anesthesia. AJCC TNM 2010 was used for staging [10]. According to the radiotherapy technique patients were divided into two groups: Group 1 (2D Conventional Radiotherapy (2DRT) patients treated in 2004 and before, Group II (3DCRT and VMAT technique) patients treated after the year 2005. Ethical approval for this study was obtained from the Non-interventional Studies Ethics Committee of Dokuz Eylul University Medical Faculty (Ethics Committee approval number: 2017/29-26). Written informed consent was obtained from all patients included in the study and the data was anonymized and maintained with confidentiality. All study methods were carried out based on the Declaration of Helsinki.

\section{Treatment}

According to our protocol, the treatment policy for early-stage comprises surgery $\pm \mathrm{RT} \pm$ chemotherapy or definitive RT (for organ sparing) \pm chemotherapy; for locally advanced disease, surgery \pm RT \pm chemotherapy or definitive RT \pm chemotherapy if the patient is not eligible for surgery. Cases who underwent surgery and treated with adjuvant RT+/- chemotherapy were not included in this study. Concomitant chemotherapy was given as $75-100 \mathrm{mg} / \mathrm{m}^{2}$ cisplatin on days $1,22,43$ depending on the patient's comorbid condition. Cisplatin-based induction chemotherapy was applied in patients with bulky disease and good performance status. According to tumor location radiotherapy was delivered to hypopharynx and involved lymph nodes by using parallel-opposed fields for the upper part of the neck and an anterior supraclavicular field for the lower part or 2 oblique wedged fields in Group I patients; between the years 2005-2014, noncoplanar multiple fields (3-7 fields) and after the year 2014 VMAT technique (simultaneous integrated boost) was performed for the treatment in Group II patients. Low-risk CTV was irradiated 50-54 Gy as well as high-risk CTV 60 Gy, gross tumor and involved lymph nodes (GTVprimary, GTVlymph node) received at least 66-70 Gy. In all patients the prescribed dose did not exceed $70 \mathrm{~Gy}$.

\section{Follow-up}


Patients were examined weekly during treatment. Treatment response was evaluated clinically and radiological 3-4 months after the completion of radiotherapy. Response Evaluation Criteria in Solid Tumors (RECIST) were used to quantify the efficacy of RT treatment according to the degree of tumour regression [11]. The acute and late side effects were evaluated and graded according to Radiotherapy and Oncology Group (RTOG) / European Organization for Research and Treatment of Cancer (EORTC) criteria. Upon treatment completion, patients were followed up every 2 to 3 months in the first 2 years, then every 6 months until 5 years and annually thereafter. Routine clinical follow-up included physical examination, a complete airway evaluation including flexible endoscopy and if necessary, direct endoscopy with anesthesia. CT/MRI scan or PET-CT was performed, if clinically indicated. Patients with recurrence were evaluated for individual salvage treatments, considering primary treatments.

\section{Statistical analysis}

Survival rates were estimated using the Kaplan-Meier method. Overall survival (OS) was calculated from the dates of diagnosis to the date of death. Disease-specific survival (DSS) and local regional relapse-free survival (LRRFS) was calculated from the dates of diagnosis to death caused by HSCC for DSS and the date of first locoregional recurrence for LRRFS. For univariate and multivariate analyses Log-rank and Cox regression tests were used. The follow-up time was calculated from the last day of RT. The SPSS statistical program (version 18.0, Chicago, IL, USA) was used for statistical analysis. P-values less than 0.05 were considered significant.

\section{Results}

The median age of the patients was $58(13-83)$ and $56(67.5 \%)$ of them were male. The distributions of patients in Group 1 and Group 2 are given in Table 1. Nine patients (29.3\%) in Group 1 and 36 (\%72.0) patients in Group 2 were treated with concomitant chemotherapy. Additionally, 3 (9.7\%) patients in Group 1 and 2 patients $(4.0 \%)$ in Group 2 were treated with concurrent chemotherapy after cisplatin-based induction therapy. All (\%100) patients had Karnofsky performance score (KPS) > 70, 24 (29\%) had a comorbid disease and $40(48 \%)$ patients had a weight loss of $5 \%$ or more in the last 6 months. A prophylactic percutaneous endoscopic gastrostomy (PEG) tube was placed in 5 (16.1\%) patients in Group 1 and 11 (22.0\%) patients in Group 2. While 7 (22.6\%) patients in Group 1 and $3(6.0 \%)$ patients in Group 2 needed parenteral nutrition (gastrostomy) during treatment, nasogastric feeding was administered to one patient in each group. 
Table 1

Patient and tumor characteristics

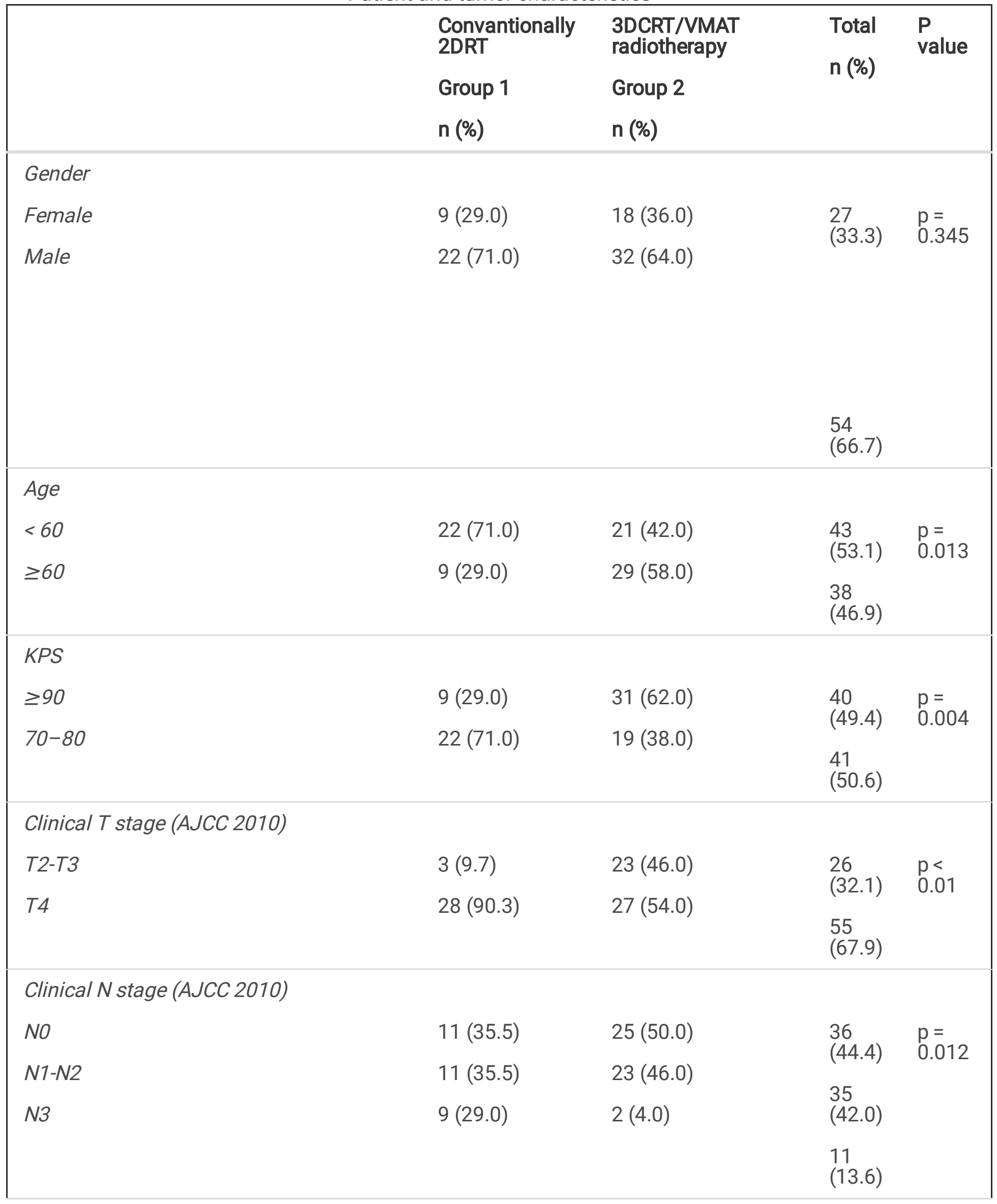




\begin{tabular}{|c|c|c|c|c|}
\hline & $\begin{array}{l}\text { Convantionally } \\
\text { 2DRT } \\
\text { Group } 1 \\
\text { n (\%) }\end{array}$ & $\begin{array}{l}\text { 3DCRT/VMAT } \\
\text { radiotherapy } \\
\text { Group } 2 \\
\mathrm{n}(\%)\end{array}$ & $\begin{array}{l}\text { Total } \\
\text { n (\%) }\end{array}$ & $\begin{array}{l}\mathrm{P} \\
\text { value }\end{array}$ \\
\hline \multicolumn{5}{|l|}{ Clinical stage (AJCC 2010) } \\
\hline \multirow[t]{3}{*}{ Stage 3} & \multirow[t]{3}{*}{$1(3.2)$} & \multirow[t]{3}{*}{$11(22.0)$} & $\begin{array}{l}12 \\
(14.8)\end{array}$ & \multirow[t]{3}{*}{$\begin{array}{l}p= \\
0.013\end{array}$} \\
\hline & & & $\begin{array}{l}57 \\
(70.4)\end{array}$ & \\
\hline & & & \multirow[t]{3}{*}{$\begin{array}{l}12 \\
(14.8)\end{array}$} & \\
\hline Stage $4 a$ & $21(67.8)$ & $36(72.0)$ & & \\
\hline Stage $4 b$ & $9(29.0)$ & $3(6.0)$ & & \\
\hline \multicolumn{5}{|l|}{ Chemotherapy } \\
\hline \multirow{3}{*}{$\begin{array}{l}\text { No chemotherapy } \\
\text { Neoadjuvant chemotherapy + concurrent } \\
\text { chemotherapy }\end{array}$} & $22(71.0)$ & $14(28.0)$ & \multirow{2}{*}{$\begin{array}{l}36 \\
(44.4)\end{array}$} & \multirow{4}{*}{$\begin{array}{l}\mathrm{p}< \\
0.01\end{array}$} \\
\hline & $3(9.7)$ & $2(4.0)$ & & \\
\hline & $6(19.4)$ & $34(68.0)$ & $\begin{array}{l}5 \\
(6.2)\end{array}$ & \\
\hline Concurrent chemotherapy & & & $\begin{array}{l}40 \\
(49.4)\end{array}$ & \\
\hline Total & $31(100)$ & $50(100)$ & $\begin{array}{l}81 \\
(100)\end{array}$ & \\
\hline
\end{tabular}

The median RT dose was 70 (60-72) Gy for patients treated before the year 2014 and 69 (66-70) Gy for treatment after the year 2014. The median follow-up time was 15 (2-266) months. Two and 5 year OS rates were $27.4 \%, 20.6 \%$ in Group 1 and $58.3 \%, 42.1 \%$ in Group 2 patients respectively (Table 2, Fig. 1). This difference in survival rates between the two groups was significant in univariate and multivariate analysis $(p=0.035, p=0.049$, Table $2-3)$. Age, $N$ stage, T stage, and KPS were found statistical significance prognostic factors affecting OS in univariate and multivariate analyses (Table 2-3). Two and 5 years localregional relapse-free survival (LRRFS) rates were 34.7\%, 29.8\% in Group 1, 79.5\%, 72.9\% in Group 2 patients, DSS rates were $31.5 \%, 27 \%$ in Group 1 and $63.5 \%, 52.7 \%$ in Group 2 patients respectively (Table 2, Fig. 2-3). In the univariate analysis, a statistically significant difference was found between the two groups in terms of both LRRFS and DSS $(p<0.001, p=0.004)$, but in multivariate analysis, only LRRFS was statistically significant $(p=0.025$ and $p=0.106)$. Chemotherapy was found to be a significant prognostic factor for LRRFS and DSS in univariate analysis, but no impact on OS $(p=0.005, p=0.005, p=0.129)$. No statistically significant difference was found between the groups with and without chemotherapy in terms of side effects $(p=0.402)$. Most of the patients had skin, mucosal and salivary gland RTOG/EORTC grade $1-2$ side effects during treatment but grade 3-4 early side effects were higher in Group 1 (20.3\%) than in Group 2 
patients $(3.1 \%, p=0.04)$. In long-term follow-up, there was a statistically significant difference in favor of Group $2(p=0.038)$. 
Table 2

Survivals rates and univariate analysis

\begin{tabular}{|c|c|c|c|c|c|c|c|c|c|c|}
\hline \multirow[t]{2}{*}{ Variables } & \multicolumn{4}{|c|}{ Overall survival } & \multicolumn{3}{|c|}{$\begin{array}{l}\text { Local-regional relapse- } \\
\text { free survival }\end{array}$} & \multicolumn{3}{|c|}{$\begin{array}{l}\text { Disease-specific } \\
\text { survival }\end{array}$} \\
\hline & $\begin{array}{l}\text { N. } \\
(\%)\end{array}$ & $\begin{array}{l}2 \\
\text { years } \\
(\%)\end{array}$ & $\begin{array}{l}5 \\
\text { years } \\
(\%)\end{array}$ & $\begin{array}{l}\mathrm{P} \\
\text { value }\end{array}$ & $\begin{array}{l}2 \\
\text { years } \\
\text { (\%) }\end{array}$ & $\begin{array}{l}5 \\
\text { years } \\
(\%)\end{array}$ & $\begin{array}{l}P \\
\text { value }\end{array}$ & $\begin{array}{l}2 \\
\text { years } \\
(\%)\end{array}$ & $\begin{array}{l}5 \\
\text { years } \\
(\%)\end{array}$ & $\begin{array}{l}\mathrm{P} \\
\text { value }\end{array}$ \\
\hline \multicolumn{11}{|l|}{ Gender } \\
\hline Male & \multirow{2}{*}{$\begin{array}{l}54 \\
(66.7) \\
27 \\
(33.3)\end{array}$} & 52.7 & 35.1 & \multirow[t]{2}{*}{0.354} & 63.4 & 58.2 & \multirow[t]{2}{*}{0.200} & 51.8 & 42.9 & \multirow[t]{2}{*}{0.310} \\
\hline Female & & 37.6 & 32.9 & & 51.8 & 51.8 & & 45.0 & 45.0 & \\
\hline \multicolumn{11}{|l|}{ Age (years) } \\
\hline & $\begin{array}{l}43 \\
(53.1)\end{array}$ & & 36.0 & \multirow[t]{2}{*}{0.364} & 72.6 & 62.2 & \multirow[t]{2}{*}{0.108} & 56.6 & 42.0 & \multirow[t]{2}{*}{$0.42 \varepsilon$} \\
\hline$\geq 60$ & $\begin{array}{l}38 \\
(46.9)\end{array}$ & 38.7 & 31.4 & & 51.3 & 47.4 & & 44.9 & 41.4 & \\
\hline \multicolumn{11}{|l|}{$K P S$} \\
\hline$\geq 90$ & $\begin{array}{l}40 \\
(49.4)\end{array}$ & 73.8 & 57.6 & \multirow{2}{*}{$\begin{array}{l}< \\
0.001\end{array}$} & 78.0 & 78.0 & \multirow{2}{*}{$\begin{array}{l}< \\
0.001\end{array}$} & 67.0 & 63.8 & \multirow{2}{*}{$\begin{array}{l}<.001 \\
0.00\end{array}$} \\
\hline $70-80$ & $\begin{array}{l}41 \\
(50.6)\end{array}$ & 22.2 & 11.9 & & 41.9 & 31.4 & & 32.8 & 20.5 & \\
\hline \multicolumn{11}{|l|}{ T stage } \\
\hline T23 & $\begin{array}{l}26 \\
(32.1)\end{array}$ & 79.3 & 48.0 & \multirow[t]{2}{*}{0.002} & 89.8 & 89.8 & \multirow{2}{*}{$\begin{array}{l}< \\
0.001\end{array}$} & 78.3 & 73.0 & \multirow{2}{*}{$\begin{array}{l}<.001 \\
0.00\end{array}$} \\
\hline$T-4$ & $\begin{array}{l}68 \\
(67.9)\end{array}$ & 30.2 & 25.7 & & 44.4 & 40.0 & & 34.3 & 28.3 & \\
\hline \multicolumn{11}{|l|}{ N stage } \\
\hline No & $\begin{array}{l}36 \\
(44.4)\end{array}$ & 53.7 & 43.8 & \multirow[t]{2}{*}{0.012} & 67.1 & 67.1 & \multirow[t]{2}{*}{0.049} & 64.1 & 64.1 & \multirow[t]{2}{*}{0.014} \\
\hline$N(+)$ & $\begin{array}{l}45 \\
(55.6)\end{array}$ & 40.0 & 25.5 & & 53.3 & 45.6 & & 37.1 & 26.4 & \\
\hline \multicolumn{11}{|l|}{ Stage } \\
\hline Stage 2-3 & $\begin{array}{l}12 \\
(14.8)\end{array}$ & 75.0 & 56.3 & \multirow[t]{2}{*}{0.047} & 100 & 100 & \multirow[t]{2}{*}{0.005} & 83.3 & 83.3 & \multirow[t]{2}{*}{0.010} \\
\hline Stage 4 & $\begin{array}{l}69 \\
(85.2)\end{array}$ & 41.2 & 30.0 & & 51.5 & 47.5 & & 42.0 & 34.7 & \\
\hline
\end{tabular}




\begin{tabular}{|c|c|c|c|c|c|c|c|c|c|c|}
\hline \multicolumn{2}{|l|}{ Variables } & \multicolumn{3}{|c|}{ Overall survival } & \multicolumn{3}{|c|}{$\begin{array}{l}\text { Local-regional relapse- } \\
\text { free survival }\end{array}$} & \multicolumn{3}{|c|}{$\begin{array}{l}\text { Disease-specific } \\
\text { survival }\end{array}$} \\
\hline \\
\hline Yes & 44 & 58.3 & 43.2 & 0.045 & 73.0 & 67.0 & 0.024 & 62.6 & 54.4 & 0.010 \\
\hline No & $\begin{array}{l}37 \\
(45.7)\end{array}$ & 31.3 & 21.9 & & 42.1 & 42.1 & & 31.3 & 27.4 & \\
\hline \multicolumn{11}{|l|}{ RT technique } \\
\hline $\begin{array}{l}\text { Conventionally } \\
\text { 3DCRT/VMAT }\end{array}$ & $\begin{array}{l}31 \\
(38.3) \\
50 \\
(61.7)\end{array}$ & $\begin{array}{l}27.4 \\
58.3\end{array}$ & $\begin{array}{l}20.6 \\
42.1\end{array}$ & 0.035 & $\begin{array}{l}34.7 \\
79.5\end{array}$ & $\begin{array}{l}29.8 \\
72.9\end{array}$ & $\begin{array}{l}<.001 \\
0.00\end{array}$ & $\begin{array}{l}31.5 \\
63.5\end{array}$ & $\begin{array}{l}27.0 \\
52.7\end{array}$ & 0.004 \\
\hline
\end{tabular}

Table 3

Multivariate analyses of factors associated with overall survival, local-regional relapse-free survival and disease-specific survival

\begin{tabular}{|llll|}
\hline Variable & $\begin{array}{l}\text { Overall } \\
\text { survival }\end{array}$ & $\begin{array}{l}\text { local-regional relapse-free } \\
\text { survival }\end{array}$ & $\begin{array}{l}\text { Disease-spesific } \\
\text { survival }\end{array}$ \\
\hline Gender & P value & P value & P value \\
\hline Age & 0.142 & 0.373 & 0.135 \\
\hline KPS & $\mathbf{0 . 0 2 7}$ & 0.477 & 0.213 \\
\hline Clinical T stage & $\mathbf{0 . 0 0 1}$ & $\mathbf{0 . 0 0 2}$ & $\mathbf{0 . 0 0 1}$ \\
\hline Clinical N stage & $\mathbf{0 . 0 0 1}$ & $\mathbf{0 . 0 2 0}$ & $\mathbf{0 . 0 0 1}$ \\
\hline Stage & $\mathbf{0 . 0 1 3}$ & $\mathbf{0 . 0 2 6}$ & $\mathbf{0 . 0 1 8}$ \\
\hline Chemotherapy & 0.072 & 0.741 & 0.210 \\
\hline $\begin{array}{l}\text { Radiotherapy } \\
\text { Technique }\end{array}$ & 0.531 & 0.239 & 0.213 \\
\hline
\end{tabular}

\section{Discussion}

Advanced RT technique and planning systems (IMRT, VMAT, etc.), provide significantly better results in terms of target coverage and dose constraints. In our study, the cases were treated with 2DRT before the year 2004, and 3DCRT or VMAT technique after the year 2005. The clinical T2 / T3 disease was found to be $28.9 \%$ in Group 2 and 3.6\% in Group 1. The distribution of patients in terms of T4 disease was high in Group 1 (Table 1). Node negative disease was mostly in Group 2, whereas the distributions of N2/N3 cases were similar. Furthermore, early-stage (stage 3) disease was detected at a higher rate in Group 2 and almost all 
cases in Group 1 were stage 4 disease (Table 1). A statistically significant difference was found between the two groups in terms of stage $(p=0.013)$. The reason for this difference can be explained by the fact that RT applications for organ preservation before 2004 were rare and surgery was preferred in the early stages of hypopharyngeal carcinoma. However, in the current treatment modality, surgery has been replaced by RT or CRT in early-stage disease $[12,13,14]$.

Many studies have emphasized the prognostic significance of clinical $\mathrm{T}$ and $\mathrm{N}$ stages in patients with hypopharyngeal cancer $[14,15,16]$. In our study, $T$ and $N$ stages were found to be prognostic factors affecting both $\mathrm{OS}(\mathrm{p}=0.001, \mathrm{p}=0.035)$ and $\operatorname{LRRFS}(\mathrm{p}=0.02, \mathrm{p}=0.026)$ in multivariate analysis. Excluding stage 3 patients, and analyzing only stage $4 \mathrm{~A}$ and $4 \mathrm{~B}$ patients on both arms revealed a similar result in terms of $T$ and $N$ stages $(p=0.034, p=0.044$ and $p=0.05, p=0.045)$. Advanced age was found to be a prognostic factor affecting OS, but we detected that elderly patients with long-term follow-up patients died due to comorbid disease $(p=0.027)$. Besides, we believe that elderly patients with comorbid diseases may experience higher rates of toxicity.

Concurrent chemotherapy application was also significantly higher in Group 2 for the same reason $(p<$ $0.01)$. In the literature, an increase in concurrent chemotherapy applications has been reported after the year $2000[17,18,19,20]$. In a meta-analysis of 93 randomized trials, the efficacy of concomitant chemoradiotherapy in locally advanced heads and necks cancers has been demonstrated [21]. The use of concurrent chemoradiation is supported by extrapolation from larynx cancer and subgroup analysis of head and neck cancer trials $[3,4]$. There is however still some level of equipoise in the optimal management of locally advanced hypopharynx cancer and the assumed equivalence of organ preserving and surgery is contested in T4 disease [22]. In our study, 45 (54.2\%) patients underwent concurrent chemotherapy. Localregional control and disease-specific survival was better in patients who underwent concurrent chemotherapy $(p=0.024, p=0.010)$.

In terms of radiotherapy technique, one of the largest series of studies in the literature, Gupta et al. evaluated 501 hypopharyngeal cancer patients treated with conventional methods [23]. At a median follow-up of 12 months, the 3-year local-regional control rate was $50 \%$ for T1-2 tumors and $43.1 \%$ for T3-4 tumors. In addition, Blanchard et al. reported 5-year local and regional control rates as $68 \%$ and $69 \%$ respectively in 249 piriform sinus cases who underwent radical radiotherapy [6]. Huang et al. evaluated 33 patients with hypopharyngeal cancer and reported a 3-year locoregional control rate $68.2 \%$ at a median follow-up of 18.8 months treated definitively with Intensity Modulated Arc Therapy (IMRT) technique [24]. In a study conducted by Reis et al. the 2 and 5-year overall survival (OS) and disease-free survival rates (DFS) in 25 hypopharyngeal cancer patients treated with 3DCRT, (IMRT) or VMAT technique were reported as $47.5 \%$, $29.2 \%$ and $39.1 \%, 24.1 \%$ respectively [25]. In our study, the 2 and 5-year OS and loco-regional control rates were $27.4 \%, 20.6 \%$ and $34.7 \%, 29.8 \%$ in Group 1 and $58.3 \%, 42.1 \%$ and $79.5 \%, 72.9 \%$ in Group 2 respectively $(p=0.035, p<0.001)$. Results were found to be statistically significant in favor of Group 2 and were consistent with similar studies in the literature.

In a study published in 2015 by Mok et al., IMRT and 3DCRT techniques were compared in the treatment of patients with hypopharyngeal cancer and a higher local control rate was detected in patients treated with 
IMRT than in 3DCRT (75\% vs 58\%; p: 0.003). There was no difference in terms of OS and DFS [26]. In a similar single-center study conducted by Katsoulakis et al. in 2015, comparing 3DCRT and IMRT techniques in hypopharyngeal cancer patients, no difference was found between the two groups in terms of local control and OS [27]. Bertelsen et al. showed that doses of organs at risk can be reduced if patients with hypopharyngeal carcinoma treated with VMAT compared to IMRT technique [28]. Suat et al. evaluated the data of 3928 hypopharyngeal cancer patients in 2018 and in terms of RT technique overall survival advantage was found in IMRT Group $(p=0.013)$ [29]. In addition, few studies have shown that treatment with image-guided radiotherapy (IGRT) which is a new technology increases the local-regional control rate in patients with head and neck cancer [30, 31]. In our clinic since 2014 patients with hypopharyngeal cancer are treated with VMAT technique with daily image guidance. This new technology treatment modality has led to both a reduction in side effects and an increase in local control rates. Additionally, multivariate analysis revealed a better LRRFS rate in patients in Group 2 receiving RT with new technology $(p=0.025)$. The increase in local-regional control improved both OS and DSS. This difference was appreciated not only to be caused by modern methods of treatment, but also by the difference in stage and number of patients between the groups. However, in multivariate analyses, the fact that RT technique was found to be a significant factor can be interpreted as the positive effect of modern technology in this patient group. This group of patients after the effective results of radiotherapy in function preservation shows justification for the use of radiotherapy to improve survival and quality of life with modern techniques.

In a study published by Fu-Min Fang et al in 2006, patients treated with conventional and 3DCRT were evaluated for side effects and quality of life scores were found statistically significant in favor of patients treated with 3DCRT $(p=0.02)$ [32]. Two separate prospective studies have reported that long-term side effects are less frequent in patients who are treated with modern RT systems compared to conventional methods since the pharyngeal constrictor muscles involved in swallowing function receive fewer doses [33, 34]. Lee et al. reported that patients with hypopharyngeal cancer may require a feeding tube because of stricture after CRT [35]. Mok et al. in a study comparing IMRT and 3DCRT treatment techniques, there was no difference between the two groups in terms of feeding tube [26]. Al-Mamgani et al. detected less permanent dependence on PEG in patients planned with IMRT than the conventional method [5]. In our study, 16 patients underwent PEG during treatment and 3 of these had persistent PEG due to limitation of oral intake and pharyngeal stricture after treatment and this difference was statistically significant between two groups against Group $1(p=0.035)$. Grade $3-4$ early side effects were significantly more frequent in Group I patients than in Group II patients $(p=0.04)$. The reason for the higher incidence of side effects in Group I patients can be interpreted as the fact that the dose distribution outside the planning target volume could not be kept at an intended level in patients planned by a conventional method. Besides, in Group 2, the dose could be applied to the target volume with a more homogeneous dose distribution and close safety margins while preserving the healthy tissues with the 3DCRT / VMAT technique. With the advantage of the new technology, the late side effect was more often in Group I $(p=0.038)$.

The limitations of our study were the different patient number and stage distribution between the groups, non-randomized study and the numbers of patients receiving chemotherapy were high in Group 2. The use of PET-CT in staging method is an important evolution which can certainly confound the findings of this study and the result of better staging could influence the difference in cancer control outcomes. However, it 
is important to achieve similar results obtained in prospective studies with selected patient groups in routine practice.

In conclusion, with the use of chemoradiotherapy and new technology RT methods proposed in the literature higher local-regional control rates could be obtained with lower side effects. It is seen that longer life expectancy with better organ function can be achieved with new treatment methods. The development and widespread use of new technological treatments with prospective protocols is recommended.

\section{References}

1. Sanderson RJ, Ironside JA. Squamous cell carcinomas of the head and neck. BMJ. 325, 822-827. https://doi.org/10.1136/bmj.325.7368.822 (2002).

2. Kuo P, Chen MM, Decker RH, Wendell GY, Benjamin LJ. Hypopharyngeal cancer incidence, treatment, and survival: temporal trends in the United States. Laryngoscope 124, 2064-2069. https://doi.org/10.1002/lary.24651 (2014).

3. Blanchard P. et al. Meta-analysis of chemotherapy in head and neck cancer (MACH-NC): A comprehensive analysis by tumour site. Radiother. Oncol. 100, 33-40. https://doi.org/10.1016/j.radonc.2011.05.036 (2011).

4. Lacas B. et al. Meta-analysis of chemotherapy in head and neck cancer (MACH-NC): An update on 107 randomized trials and 19,805 patients, on behalf of MACH-NC Group. Radiother. Oncol. 156, 281-293. https://doi.org/10.1016/j.radonc.2021.01.013 (2021).

5. Al-Mamgani A et al. Toxicity, quality of life, and functional outcomes of 176 hypopharyngeal cancer patients treated by (chemo)radiation: the impact of treatment modality and radiation technique. Laryngoscope 122, 1789-1795. https://doi.org/10.1002/lary.23387 (2012).

6. Blanchard P. et al. Definitive radiotherapy for squamous cell carcinoma of the pyriform sinus. Radiother. Oncol. 105, 232-237. https://doi.org/10.1016/j.radonc.2012.09.004 (2012).

7. Forastiere AA. et al. Long-term results of Intergroup RTOG 91-11: A phase III trial to preserve the larynx Induction cisplatin/5-FU and radiation therapy versus concurrent cisplatin and radiation therapy versus radiation therapy. Journal of Clinical Oncology 5517, 18S. https://doi.org/10.1200/JC0.2012.43.6097 (2006).

8. Lefebvre JL. et al. Larynx preservation in pyriform sinus cancer: preliminary results of a European Organization for Research and Treatment of Cancer phase III trial. EORTC Head and Neck Cancer Cooperative Group. J. Natl. Cancer Inst. 88, 890-899. https://doi.org/10.1093/jnci/88.13.890 (1996).

9. Lefebvre JL. et al. Laryngeal preservation with induction chemotherapy for hypopharyngeal squamous cell carcinoma: 10-year results of EORTC trial 24891. Annals of Oncology 23, 2708-2714. https://doi.org/10.1093/annonc/mds065 (2012).

10. Edge, S. American Joint Committee on Cancer (AJCC). Cancer staging handbook 7th ed. (Lippincott Williams \& Wilkins, 2010).

11. Eisenhauer EA. et al. New response evaluation criteria in solid tumours: Revised RECIST guideline (version 1.1). Eur. J. Cancer 45, 228-47. https://doi.org/10.1016/j.ejca.2008.10.026 pmid:19097774 
(2009).

12. Newman JR. et al. Survival trends in hypopharyngeal cancer: a population-based review. Laryngoscope 125, 624-629. https://doi.org/10.1002/lary.24915 (2015).

13. Takes RP. et al. Current trends in initial management of hypopharyngeal cancer: the declining use of open surgery. Head Neck 34, 270-281. https://doi.org/10.1002/hed.21613 (2012).

14. Taguchi T. et al. Treatment results and prognostic factors for advanced squamous cell carcinoma of the hypopharynx treated with concurrent chemoradiotherapy. Cancer Chemother. Pharmacol. 73, 11471154. https://doi.org/10.1007/s00280-014-2448-2 (2014).

15. Wang YL. et al. Impact of lymph node ratio on the survival of patients with hypopharyngeal squamous cellcarcinoma: a population-based analysis. PLoS One 8, e56613. https://doi.org/10.1371/journal.pone.0056613 (2013).

16. Krstevska V, Stojkovski I, Zafirova-Ivanovska B, Crvenkova S. Prognostic factors in patients with advanced hypopharyngeal squamous cell carcinoma treated with concurrent chemoradiotherapy. $J$. BUON 17, 327-336 (2012).

17. Forastiere AA. et al. Concurrent chemotherapy and radiotherapy for organ preservation in advanced laryngeal cancer. N. Engl. J. Med. 349, 2091-2098. https://doi.org/10.1056/NEJMoa031317 (2003).

18. Prades JM. et al. Randomized phase III trial comparing induction chemotherapy followed by radiotherapy to concomitant chemoradiotherapy for laryngeal preservation in T3M0 pyriform sinus carcinoma. Acta Otolaryngol. 130, 150-155. https://doi.org/10.3109/00016480902914080 (2010).

19. Lefebvre JL. et al. Laryngeal preservation with induction chemotherapy for hypopharyngeal squamous cell carcinoma: 10-year results of EORTC trial 24891 Ann. Oncol. 23, 2708-2714. https://doi.org/10.1093/annonc/mds065 (2012).

20. Lefebvre J. et al. Phase 3 randomized trial on larynx preservation comparing sequential vs alternating chemotherapy and radiotherapy. J. Natl. Cancer Inst. 101, 142-152. https://doi.org/10.1093/jnci/djn460 (2009).

21. Pignon JP, le Maitre A, Maillard E, Jean B. Meta-analysis of chemotherapy in head and neck cancer (MACH-NC): An update on 93 randomised trials and 17,346 patients. Radiother. Oncol. 92, 4-14. https://doi.org/10.1016/j.radonc.2009.04.014 (2009).

22. Hall SF, Griffiths R. Did the addition of concomitant chemotherapy to radiotherapy improve outcomes in hypopharyngeal cancer? A population-based study. Curr. Oncol. 23, 266-72. https://doi.org/10.3747/co.23.3085 (2016).

23. Gupta T. et al. Squamous cell carcinoma of the hypopharynx: single-institution outcome analysis of a large cohort of patients treated with primary non-surgical approaches. Acta Oncol. 48, 541-548. https://doi.org/10.1080/02841860802488839 (2009).

24. Huang WY. et al. Intensity modulated radiotherapy with concurrent chemotherapy for larynx preservation of advanced resectable hypopharyngeal cancer. Radiat. Oncol. 5, 37. https://doi.org/10.1186/1748-717X-5-37 (2010).

25. Reis I. et al. Locally advanced hypopharyngeal squamous cell carcinoma: single-institution outcomes in a cohort of patients curatively treated either with or without larynx preservation. Radiol. Bras. 49, 21- 
25. https://doi.org/10.1590/0100-3984.2015.0018 (2016).

26. Mok G. et al. Outcomes of intensity-modulated radiotherapy versus conventional radiotherapy for hypopharyngeal cancer. Head Neck 37, 655-661. https://doi.org/10.1002/hed.23649 (2015).

27. Evangelia K. et al. Hypopharyngeal Squamous Cell Carcinoma: Three-Dimensional or IntensityModulated Radiotherapy? A Single Institution's Experience Laryngoscope 126, 620-626. https://doi.org/10.1002/lary.25509 (2016).

28. Bertelsen A, Hansen CR, Johansen J, Carsten B. Single Arc Volumetric Modulated Arc Therapy of head and neck cancer. Radiother. Oncol. 95, 142-148. https://doi.org/10.1016/j.radonc.2010.01.011 (2010).

29. Suat K. et al. Radiotherapy modality as a predictor of survival in hypopharyngeal cancer. Head Neck 40, 2441-2448. https://doi.org/10.1002/hed.25360 (2018).

30. Nguyen NP. et al. Feasibility of intensity-modulated and image-guided radiotherapy for functional organ preservation in locally advanced laryngeal cancer. PLoS One 7, e42729. https://doi.org/10.1371/journal.pone.0042729 (2012).

31. Nguyen NP. et al. Feasibility of tomotherapy-based image-guided radiotherapy for locally advanced oropharyngeal cancer. PLoS One 8, e60268. https://doi.org/10.1371/journal.pone.0060268 (2013).

32. Fang FM. et al. Intensity-modulated or Conformal Radiotherapy Improves the Quality of Life of Patients With Nasopharyngeal Carcinoma. Comparisons of Four Radiotherapy Techniques. Cancer 109, 313321. https://doi.org/10.1002/cncr.22396 (2007).

33. Eisbruch A. et al. Chemo-IMRT of oropharyngeal cancer aiming to reduce dysphagia: swallowing organs late complication probabilities and dosimetric correlates. Int. J. Radiat. Oncol. Biol. Phys. 81, e93-e99. https://doi.org/10.1016/j.ijrobp.2010.12.067 (2011).

34. Schwartz DL. et al. Candidate dosimetric predictors of long-term swallowing dysfunction after oropharyngeal intensity modulated radiotherapy. Int. J. Radiat. Oncol. Biol. Phys. 78, 1356-1365. https://doi.org/10.1016/j.ijrobp.2009.10.002 (2010).

35. Lee WT. et al. Risk factors for hypopharyngeal/upper esophageal stricture formation after concurrent chemoradiation. Head Neck 28, 808-812. https://doi.org/10.1002/hed.20427 (2006).

\section{Figures}




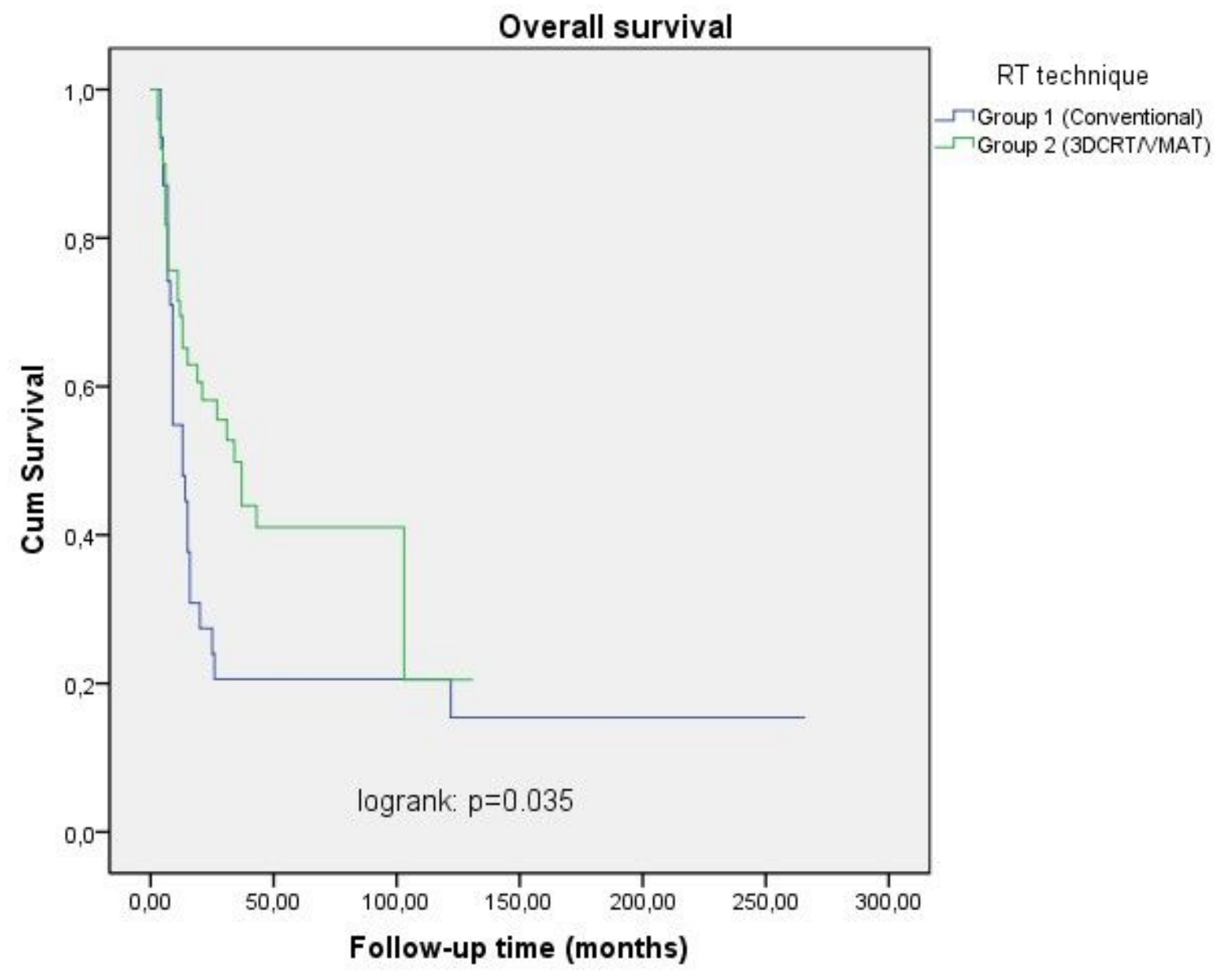

Figure 1

Kaplan-Meier curves showing overall survival according to study Groups 


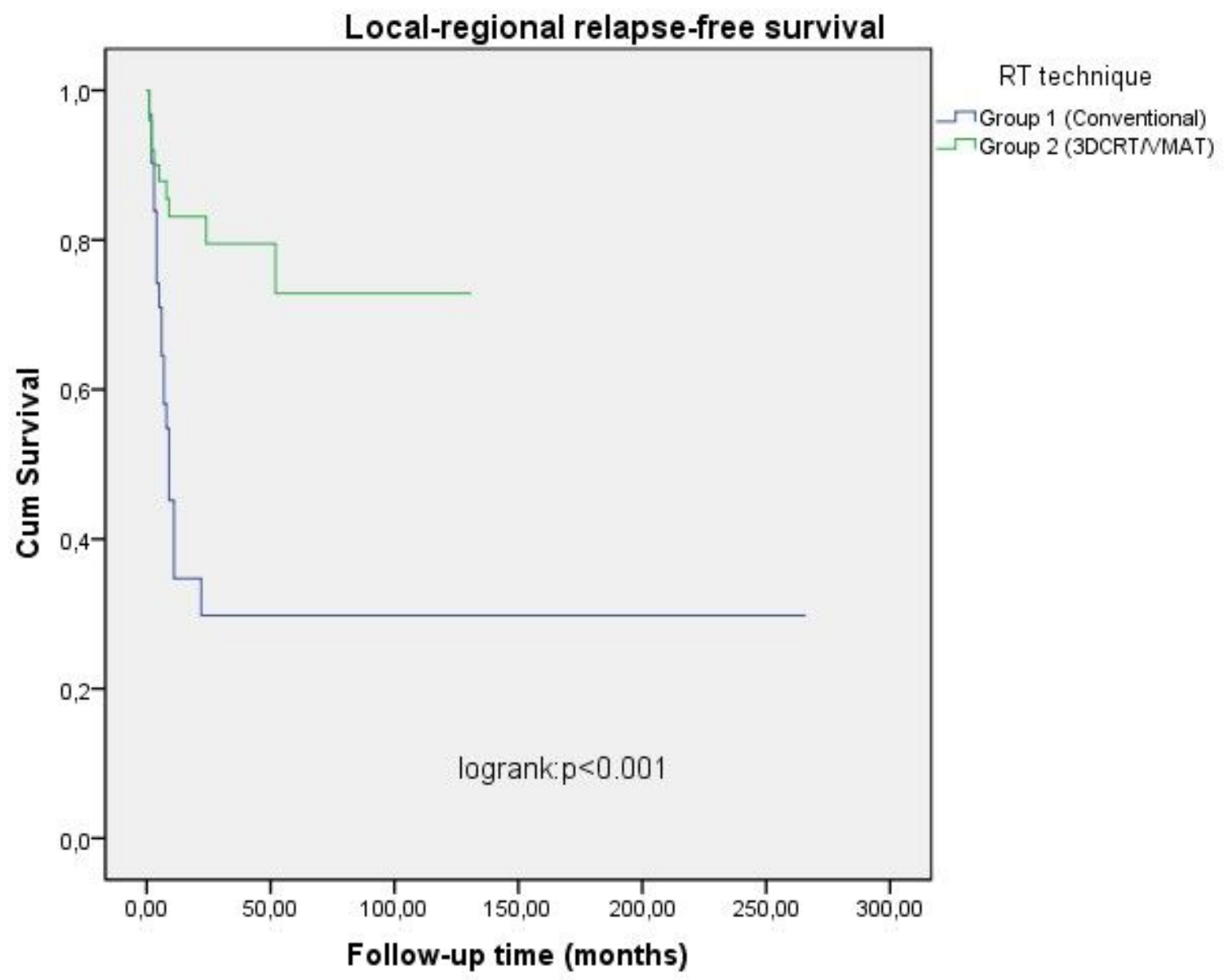

Figure 2

Kaplan-Meier curves showing local-regional relapse-free survival according to study Groups 


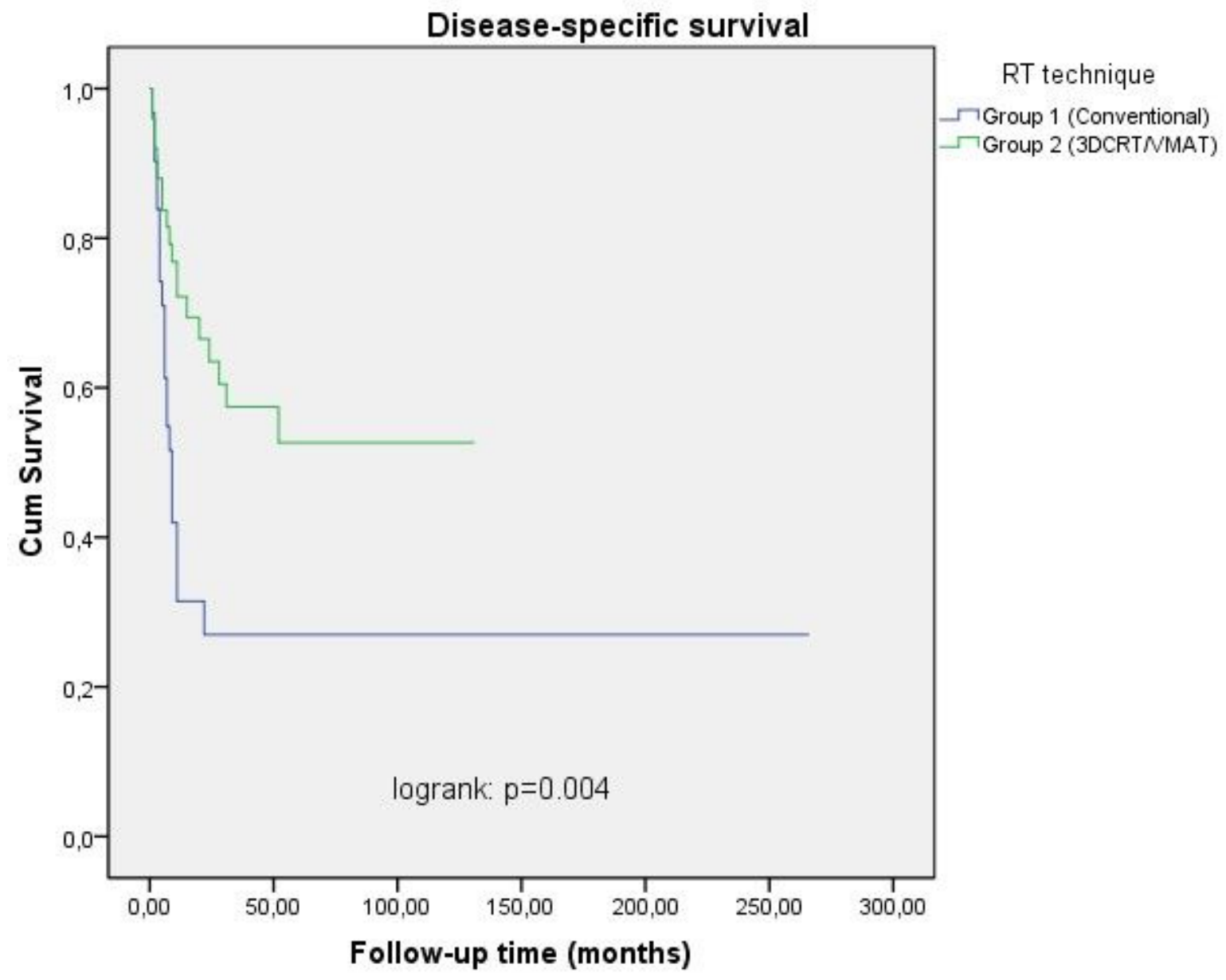

Figure 3

Kaplan-Meier curves showing disease-specific survival according to study Groups 